\title{
Comunicação
}

[Communication]

\section{Prevalência de enterococos isolados de frangos caipiras em diferentes regiões do Distrito Federal}

\author{
[Prevalence of Enterococcus spp. isolated from free-range chickens in different \\ regions of Distrito Federal, Brazil]
}

\section{D.B. Xavier, F.E.M. Bernal, R.T. Almeida}

Universidade de Brasília

70910-900 - Brasília, DF

A presença de microrganismos resistentes em animais produtores de alimentos e a possível contaminação de sua carcaça são aspectos importantes em termos de sanidade animal e de saúde pública (Moreno et al., 2006). As principais bactérias que podem representar risco ao consumidor e que têm sido objeto de atenção em programas internacionais de vigilância são Escherichia coli, Salmonella, Campylobacter e Enterococcus (Global..., 2000; Titze-de-Almeida e Palermo-Neto, 2005). Enterococos, patógenos oportunistas que habitam a microbiota do homem e de outros animais, incluindo animais de companhia, produtores de alimentos e silvestres (McDonald et al., 1997; Aarestrup et al., 2002) podem causar surtos de infecção hospitalar de difícil controle e disseminar clones epidêmicos (Titze-de-Almeida et al., 2006). Enterococos apresentam resistência intrínseca a vários antibióticos e têm adquirido novos fenótipos de resistência, destacando-se os enterococos resistentes à vancomicina (VRE) (Cetinkaya et al., 2000; Willems e Bonten, 2007).

O uso de promotores de crescimento (AGP) em aves confinadas em alta densidade possibilita a prevenção de doenças e o aumento da produtividade (Garcia et al., 2002). Porém, o uso destes AGP pode exercer pressão seletiva para enterococos resistentes, como ocorreu para a avoparcina e os VRE (Bager et al., 1997). No Brasil, dois estudos de vigilância apresentaram resultados contrastantes quanto à prevalência de VRE em frangos. O primeiro não identificou resistência à vancomicina em enterococos isolados de frangos tratados com o promotor de crescimento avoparcina (Leme et al., 2000). O segundo identificou VRE em carcaças de frangos exportadas para o Japão (Ike et al., 1999).

O mercado consumidor para frangos caipiras, tratados sem AGP, está em expansão no País (Demattê Filho e Mendes, 2001). Esse sistema de criação, normatizado pelo Ministério da Agricultura, Pecuária e Abastecimento, é classificado nos padrões do Sistema Caipira/Colonial de produção de aves de corte, via ofício circular DOI/DIPOA n. 007/99 de 19/05/1999. As aves devem ter acesso à área externa e a alimentação tem que ser exclusivamente de fontes vegetais. É proibido o uso de promotores de crescimento de qualquer tipo ou natureza, e a ave não pode receber produtos quimioterápicos $\mathrm{e}$ ingredientes de origem animal na ração (Figueiredo et al., 2001).

Considerando-se a importância global dos enterococos e as características do frango caipira no País, o presente estudo teve o objetivo de avaliar a epidemiologia dessa bactéria em frango caipira criado no Distrito Federal.

Coletaram-se, aleatoriamente, cinco amostras de frango caipira por granja para análise da prevalência de espécies de enterococos potencialmente resistentes à vancomicina, perfazendo um total de 200 suabes de animais pertencentes a 40 granjas de oito regiões do DF: Jardim, Pad/DF, Paranoá, Sobradinho, Planaltina, Rio Preto, Taquara e São Sebastião. 
As amostras foram transportadas em meio específico, BBL transport medium, Difco ${ }^{1} \mathrm{em}$ recipiente resfriado. A semeadura inicial foi realizada em meio para isolamento seletivo de enterococos, BBL Enterococcosel broth ${ }^{l}$, suplementado com vancomicina $8 \mu \mathrm{g} / \mathrm{ml}$. As amostras foram incubadas por 18 horas a $35-37^{\circ} \mathrm{C}$. Para cada ensaio de isolamento, foi realizado controle de qualidade dos meios e dos testes, utilizando-se cepas previamente identificadas por testes bioquímicos e cepas-controle American Type Culture Collection, para amostras sensíveis e resistentes à vancomicina. Foram utilizadas as seguintes cepas: E. faecalis (ATCC 29212 e 775), E. faecalis vanB (ATCC 51299), E. gallinarum (ATCC 12359) e E. faecalis vanA (A256 - Rio de Janeiro).

O crescimento positivo foi caracterizado pelo enegrecimento do meio devido à hidrólise de esculina. As amostras positivas foram semeadas em ágar sangue de carneiro $5 \%$ para avaliação das colônias, realizando-se os testes fenotípicos presuntivos. As colônias características de enterococos, com morfologia de cocos Grampositivos, negativas para catalase, foram submetidas à reação em cadeia de polimerase (PCR).

A PCR multiplex foi realizada com primers de oligonucleotídeos para identificação de genes espécie-específicos, relativos às espécies $E$. faecalis, E. faecium, E. gallinarum e $E$. casseliflavus, e dos genes de alta resistência à vancomicina vanA e vanB, conforme descrito anteriormente (Titze de Almeida et al., 2004). Foi realizada eletroforese dos produtos de PCR em gel de agarose $1 \%$ corado com brometo de etídio, sendo fotografados sob luz ultravioleta.

$\mathrm{O}$ uso de meio seletivo contendo vancomicina $8 \mu \mathrm{g} / \mathrm{ml}$ e a PCR multiplex mostraram-se efetivos para o isolamento e a identificação de espécies de enterococos a partir de suabes cloacais. De um total de 200 suabes, observou-se crescimento em 119 $(59,5 \%)$ amostras, sendo 47 classificadas em cocos Gram-positivos, catalase negativos, formando colônias típicas de enterococos. Essas colônias foram submetidas à PCR multiplex para identificação de espécies e de genes de resistência à vancomicina (Fig. 1). As espécies mais prevalentes foram E. gallinarum e E. casseliflavus (Tab. 1). Apenas um isolado foi identificado como $E$. faecalis. Os genes de alta resistência à vancomicina não foram identificados em nenhuma amostra.

Estudos anteriores utilizando isolamento seletivo mostram alto grau de variabilidade na distribuição das espécies de enterococos e na taxa de colonização de frangos. Segundo Khan et al. (2005), espécie E. gallinarum foi a mais prevalente em isolamento seletivo a partir de amostras de cama de frango de granjas industriais do estado de Arkansas. Rice et al. (2003) também usaram isolamento seletivo e identificaram $11 \%$ de colonização por enterococos VanC, porém da espécie E. casseliflavus. As espécies E. faecalis $(58,6 \%)$ e $E$. durans $(25,7 \%)$ foram prevalentes em amostras de cortes de frango em mercados da Malásia (Radu et al., 2001). As diferenças de prevalência encontradas podem ser reflexos de diferentes pressões evolucionárias, formas de manejo, ou mesmo habilidades distintas de linhagens microbianas para colonização dos animais.

Neste estudo, nove isolados com características fenotípicas e morfológicas de enterococos apresentaram resultados negativos para as quatro espécies de maior interesse em saúde pública, $E$. faecalis, E. faecium, E. casseliflavus ou $E$. gallinarum. Este resultado sugere a ocorrência de outras espécies não testadas no PCR multiplex, a exemplo de E. durans, E. avium e E. hirae, já isolados de frangos ou de seu ambiente de criação (Radu et al., 2001; Hayes et al., 2004).

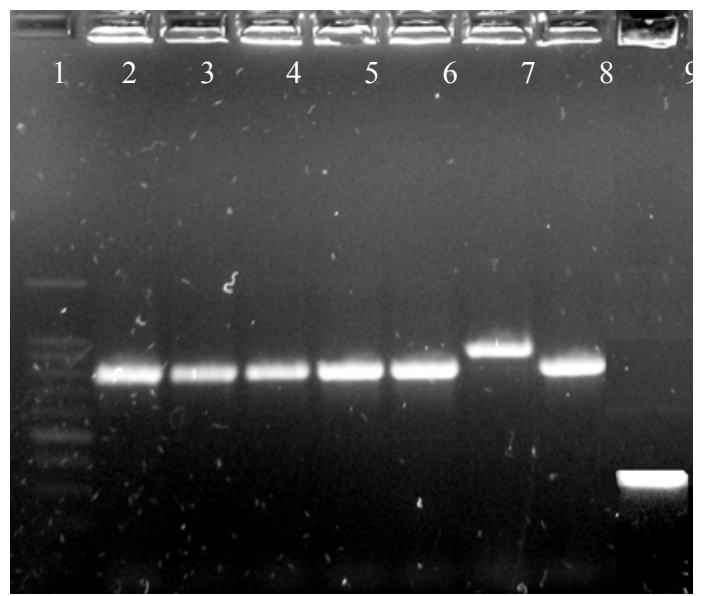

Figura 1. Eletroforese em gel de agarose (1\% das amostras isoladas); 1: Ladder 100bp; 2, 3, 4, 5, 6 e 8: E. gallinarum (822bp); 7: E. faecalis (941bp); 9: E. casseliflavus (439bp).

${ }^{1}$ Becton Dickinson and Co. - Sparks, MD, EUA. 
Tabela 1. Prevalência de espécies de enterococos em aves segundo a região do Distrito Federal

\begin{tabular}{lccccc}
\multicolumn{1}{c}{ Região } & Número & $\begin{array}{c}\text { E. gallinarum } \\
\text { número }(\%)\end{array}$ & $\begin{array}{c}\text { E. casseliflavus } \\
\text { número }(\%)^{*}\end{array}$ & $\begin{array}{c}\text { E. faecalis } \\
\text { número }(\%)^{*}\end{array}$ & $\begin{array}{c}\text { Total } \\
\text { número (\%) }\end{array}$ \\
\hline Jardim & 25 & $2(8 \%)$ & 0 & 0 & $2(8 \%)$ \\
Pad/DF & 25 & $1(4 \%)$ & $6(24 \%)$ & 0 & $7(28 \%)$ \\
Paranoá & 25 & $9(36 \%)$ & $2(8 \%)$ & 0 & $11(44 \%)$ \\
Planaltina & 25 & $6(24 \%)$ & $1(4 \%)$ & 0 & $7(28 \%)$ \\
Rio Preto & 25 & 0 & $1(4 \%)$ & 0 & $1(4 \%)$ \\
São & 25 & $1(4 \%)$ & 0 & 0 & $1(4 \%)$ \\
Sebastião & & & & & $4(16 \%)$ \\
Sobradinho & 25 & $3(12 \%)$ & 0 & 0 & $5(20 \%)$ \\
Taquara & 25 & $4(16 \%)$ & $1(4 \%)$ & 1 & $38(19 \%)$ \\
Total & 200 & $26(13 \%)$ & $11(5,5 \%)$ & 0 & 0 \\
\hline
\end{tabular}

*Percentual de isolados em relação ao número de amostras coletadas.

Um aspecto relevante no atual estudo foi a variação na taxa de colonização e na distribuição das espécies de acordo com as regiões amostradas. Paranoá, seguido de Planaltina e Pad-DF apresentaram a maior freqüência de isolamentos $(44 \%, \quad 28 \%$ e $28 \%$, respectivamente), contrastando com Rio Preto e São Sebastião, que apresentaram números reduzidos (4\% para ambos). A prevalência de cada espécie de enterococos também variou entre as regiões. Paranoá e Planaltina apresentaram alta prevalência de E. gallinarum em relação às demais regiões. $\mathrm{Na}$ região do $\mathrm{Pad} / \mathrm{DF}$, ao contrário, E. casseliflavus foi a espécie mais prevalente; Jardim e São Sebastião apresentaram apenas E. gallinarum e Rio Preto, somente E. casseliflavus. Em síntese, apesar da proximidade geográfica, observou-se marcada diferença na prevalência das espécies de acordo com a região investigada. Este achado reforça a necessidade de um delineamento experimental rigoroso em estudos epidemiológicos, evitando-se, assim, viés de seleção e de confundimento.

Em resumo, enterococos vanC das espécies $E$. gallinarum e E. casseliflavus foram predominantes em amostras de frangos caipiras do Distrito Federal, e não foram isolados genes para alta resistência à vancomicina. Identificouse, ainda, grande variação de prevalência de espécies e de taxa de colonização entre as várias regiões amostradas.

Palavras-chave: frango caipira, Enterococcus, resistência à vancomicina, VRE

\section{ABSTRACT}

It was studied whether vancomycin-resistant enterococci (VRE) colonize poultry raised without receiving antimicrobial growth promoters (AGP), in non-intensive production systems. A total of 200 cloacal swabs were colleted in farms $(n=40)$ of eight different regions of the Distrito Federal. After selective isolation, the typical enterococcal colonies were submitted to the multiplex PCR to identify enterococcal species (E. faecalis, E. faecium, E. gallinarum, and E. casseliflavus), and genes coding for high-level vancomycin resistance phenotypes. No VRE were found in the examined samples. The prevalence rates were higher for E. gallinarum $(n=26 ; 13.0 \%)$ and $\mathrm{E}$. casseliflavus $(n=11 ; 5.5 \%)$. It was found remarkable differences in the prevalence of $\mathrm{E}$. gallinarum and $\mathrm{E}$. casseliflavus among the poultry farms and studied regions, and it seems that poultry raised in non-intensive production systems in the Distrito Federal of Brazil are not reservoirs of VRE.

Keywords: poultry, Enterococcus, vancomycin resistance, nonintensive production systems, VRE

\section{REFERÊNCIAS BIBLIOGRÁFICAS}

AARESTRUP, F.M.; BUTAYE, P.; WOLGANG, W. Nonhuman reservoirs of Enterococci. In: GILMORE, M.S. (Ed). The Enterococci: pathogenesis, molecular biology, and antibiotic resistence. Washington, DC: ASM Press, 2002.

BAGER, F.; MADSEN, M.; CHRISTENSEN, J. et al. Avoparcin used as a growth promoter is associated with the occurrence of vancomycinresistant Enterococcus faecium on Danish 
poultry and pig farms. Prev. Vet. Med., v.31, p.95-112, 1997.

CETINKAYA, Y.; FALK, P.; MAYHALL, C.G. Vancomycin-resistant enterococci. Clin. Microbiol. Rev., v.13, p.686-707, 2000.

DEMATTÊ FILHO, L.C.; MENDES, C.M.I. Viabilidade técnica e econômica na criação alternativa de frangos. In: CONFERÊNCIA APINCO 2001 DE CIÊNCIA E TECNOLOGIA AVÍCOLA, 2., 2001, Campinas. Anais... Campinas: FACTA, 2001. p.255-266.

FIGUEIREDO, E.A.P.; PAIVA, D.P.; ROSA, P.S. et al. Diferentes denominações e classificação brasileira de produção alternativa de frangos. In: CONFERÊNCIA APINCO 2001 DE CIÊNCIA E TECNOLOGIA AVÍCOLA, 2., 2001. Campinas. Anais... Campinas: FACTA, 2001, p.209-222.

GARCIA, R.G.; CALDARA, F.R.; ABREU, A.P.N. et al. Perspectivas de mercado do frango certificado alternativo no estado de São Paulo. Projeto da disciplina de Tópicos em sistemas de gestão agroalimentar. Botucatu: FMVZ-UNESP, 2002.

GLOBAL principles for the containment of antimicrobial resistance in animals intended for food. $W H O / C D S / C S R$, v.4, p.1-21, 2000.

HAYES J.R.; ENGLISH L.L.; CARR, L.E. et al. Muliple-antibiotic resistance of Enterococcus spp. Isolated from commercial poultry production environments. Appl. Environ. Microbiol., v.70, p.6005-6011, 2004.

IKE, Y.; TANIMOTO, K.; OZAWA, Y. et al. Vancomycin-resistant enterococci in imported chickens in Japan. Lancet, v.353, p.1854, 1999.

KHAN, S.A.; NAWAS M.S.; KHAN, A.A. et al. Molecular characterization of multidrug-resistant Enterococcus spp. from poultry and dairy farms: detection of virulence and vancomycin resistance gene markers by PCR. Mol. Cell. Probes, v.19, p.27-34, 2005.

LEME, I.L.; PIANTINO, A.J.; PIGNATARI, A.C. Glycopeptides susceptibility among enterococci isolated from a poultry farm in São Paulo, Brazil (1996/1997). Braz. J. Microbiol., v.31, p.53-57, 2000.

MCDONALD, L.C.; KUEHNERT, M.J.; TENOVER, F.C. et al. Vancomycin-resistant enterococci outside the health-care setting: prevalence, sources, and public health implications. Emerg. Infect. Dis., v.3, p.311-317, 1997.

MORENO, M.R.F.; SARANTINOPOULOS, P.; TSAKALIDOU, E. et al. The role and application of enterococci in food and health. Int. J. Food Microbiol., v.106, p.1-24, 2006.

RADU, S.; TOOSA, H.; RAHIM, R.A. et al. Occurrence of the vanA and vanC2/C3 genes in Enterococcus species isolated from poultry sources in Malaysia. Diagn. Microbiol. Infect. Dis., v.39, p.145-153, 2001.

RICE, E.W.; BOCZEK, L.A.; JOHNSON, C.H. et al. Detection of intrinsic vancomycin resistant enterococci in animal and human feces. Diagn. Microbiol. Infect. Dis., v.46, p.155-158, 2003.

TITZE-DE-ALMEIDA, R.; ROLLO FILHO, M.; NOGUEIRA, C.A. et al. Molecular epidemiology and antimicrobial susceptibility of Enterococci recovered from Brazilian intensive care units. Braz. J. Infect. Dis., v.8, p.197-205, 2004.

TITZE-DE-ALMEIDA, R.; PALERMO-NETO, J. Uso de antimicrobianos em avicultura e o desenvolvimento de resistência bacteriana. In: PALERMO-NETO, J.; SPINOSA, H.S.; GÓRNIAK, S.L. (Eds). Farmacologia aplicada à avicultura. São Paulo: Roca, 2005. p.161-173.

TITZE-DE-ALMEIDA R.; VAN BELKUM, A.; FELIPE, M.S.S. et al. Multilocus sequence typing of hospital associated Enterococcus faecium from Brazil reveals their unique evolutionary history. Microb. Drug. Res., v.12, p.121-125, 2006.

WILLEMS, R.J.L.; BONTEN, M.J.M. Glycopeptide-resistant enterococci: deciphering virulence, resistance and epidemicity. Curr. Opin. Infect. Dis., v.20, p.384-390, 2007. 